\title{
Effect of heterogeneously distributed pre-existing dispersoids on the recrystallization behavior of a cold-rolled Al-Mn-Fe-Si alloy
}

\author{
K. Huang a,b,*, Y.J. Li ${ }^{\text {a }}$, K. Marthinsen ${ }^{\text {a }}$ \\ a Department of Materials Science and Engineering, Norwegian University of Science and Technology, N-7491 Trondheim, Norway \\ b Thermomechanical Metallurgy Laboratory - PX Group Chair. Ecole Polytechnique Fédérale de Lausanne (EPFL), CH-2002 Neuchâtel, Switzerland
}

\section{A R T I C L E I N F O}

\section{Article history:}

Received 14 December 2014

Received in revised form 21 February 2015

Accepted 23 February 2015

Available online 24 February 2015

\section{Keywords:}

Recrystallization

Texture

Precipitation

Dispersoids

Second-phase particles

Aluminum alloy

\begin{abstract}
A B S T R A C T
It is well known that strong concurrent precipitation, mainly located along grain/subgrain boundaries, results in a coarse and elongated grain structure, and unusual sharp $\mathrm{P}\{011\}<566>$ and/or $\mathrm{M}\{113\}<110>$ texture components during annealing of supersaturated AA3xxx-series alloys. In this study, a supersaturated as-cast Al-MnFe-Si alloy was annealed at three temperature-time paths after cold rolling and their effects on the softening behavior have been analyzed and compared in terms of final grain structure and texture. In particular, material conditions with dispersoids located along grain/sub-grain boundaries were produced prior to annealing. The effects of pre-existing dispersoids as well as dispersoids formed during annealing (concurrent precipitation), both of which are heterogeneously distributed along grain/sub-grain boundaries, on the recrystallization behavior of the deformed material were investigated and compared. The results clearly show that, due to their larger sizes, these pre-existing dispersoids do not significantly increase the strength of the $\mathrm{P} / \mathrm{M}$ texture components as compared to the dispersoids formed during annealing, even though the former can still affect the grain structure. It can be concluded that sharp P/M textures develop when recrystallization takes place at low temperature where nucleation of other orientations, whether from particle stimulated nucleation (PSN) or other nucleation mechanisms are suppressed by concurrent precipitation.
\end{abstract}

(c) 2015 Elsevier Inc. All rights reserved.

\section{Introduction}

Aluminum AA3xxx-series alloys have moderate strength, good ductility and excellent corrosion resistance, a very typical application is the beverage can body, as well as in packaging, building and appliances' applications. These alloys contain $\mathrm{Mn}$ as their main alloying element, while other elements like $\mathrm{Fe}, \mathrm{Si}, \mathrm{Mg}$ and $\mathrm{Cu}$ often are added to improve their mechanical properties. Most of the Fe content forms intermetallic constituent particles during solidification, while the majority of Mn content remains in solid solution, resulting in supersaturation of the solid solution. The supersaturated Mn will precipitate as fine Mn-bearing dispersoids during subsequent thermo-mechanical processing steps [1-3], thus change the microchemistry of the alloy [4].

The effect of fine dispersoids on the softening behavior of aluminum alloys during isothermal annealing has been extensively studied [4-8]. There are mainly two types of dispersoids involved during the annealing of deformed aluminum alloys. The first type belongs to the fine dispersoids present before annealing, often referred to as pre-existing dispersoids, this type of dispersoids is usually formed during homogenization

\footnotetext{
* Corresponding author at: Department of Materials Science and Engineering, Norwegian University of Science and Technology, Trondheim, N-7491 Trondheim, Norway.

E-mail address: huangke0729@hotmail.com (K. Huang).
}

and/or hot deformation and they are mostly randomly distributed. The other type is the dispersoids that precipitate concurrently with recrystallization mainly along grain/subgrain boundaries [5,8]. The precipitation of dispersoids in the course of an annealing treatment can hinder or even totally suppress recrystallization $[5,8,9]$. Except the pancakeshaped coarse grain structures, specific texture components like $\mathrm{P}$ $\{011\}<566>$, M $\{113\}<110>$ and ND-rotated cube $\{001\}<310>$ are often observed when precipitation occurs concurrently with recrystallization [4-6,8,10-13]. It is reported by Zeng et al. [10] that the concurrent precipitation effect was not the sole reason responsible for the formation of the P texture component, fine pre-existing particles also give rise to the formation of the $\mathrm{P}$ orientation. Tangen et al. [8] studied the effect of both types of dispersoids, and they observed that dispersoids present prior to cold rolling and annealing had a weaker effect on the recrystallized grain size and texture compared to concurrent precipitation. It is not totally clear, however, why concurrent precipitation has a stronger effect on recrystallization behavior than pre-existing dispersoids, although it has been speculated that it is due to their different spatial distribution and/or size. In terms of pre-existing dispersoids, existing studies have mainly focused on the effect of randomly distributed dispersoids that are present prior to annealing. The effect of nonrandomly distributed pre-existing dispersoids is mostly left unexplored. In a rare case, cold-rolled specimens of an AA3xxx-type alloy were subjected to different annealing treatments by Schäfer and Gottstein [14], 
some of the samples were annealed either at a relatively low temperature of $180^{\circ} \mathrm{C}$ for $5 \mathrm{~h}$ or at the higher temperature of $290^{\circ} \mathrm{C}$, but with only a short time of $15 \mathrm{~min}$. As shown by their backscattered electron (BSE) micrographs, no significant precipitation occurred during these annealing experiments, however, if any, it should preferably be along grain/subgrain boundaries. However, for initial conditions of a super saturated solid solution, significant amounts of concurrent precipitation take place during low temperature annealing, preferentially at highangle grain boundaries and subsequently as well on low-angle grain boundaries before the onset of recrystallization $[5,8,13]$, thus providing a condition of considerable amount of strongly heterogeneously distributed pre-existing dispersoids.

The main objective of the present work has been to establish a better understanding of the effect of pre-existing dispersoids on the recrystallized grain structure and texture of a cold-rolled Al-Mn-Fe-Si model alloy, just with focus on pre-existing dispersoids located along grain/ subgrain boundaries. For this purpose, the as-cast state of the alloy, for which no randomly distributed dispersoids are present, was cold rolled to a strain of $\varepsilon=3.0$. Theses deformed samples were then annealed with three different temperature-time schedules, i.e., isothermal annealing, step annealing and non-isothermal annealing, to various target temperatures to explore the effect of non-randomly distributed preexisting dispersoids on the microstructure and texture, which were characterized by EBSD. The effect of constituent particles was supposed to be the same for the three cases, since possible changes to the constituent particle structure are limited when annealed at $300{ }^{\circ} \mathrm{C}$ for $10^{4} \mathrm{~s}$ [3].

\section{Experimental}

The examined material was an AA3xxx-type extrusion billet of $288 \mathrm{~mm}$ in diameter, DC-casted by Hydro Aluminium. The as-received alloy was in the as-cast state, with the chemical composition (wt.\%) of $0.152 \% \mathrm{Si}, 0.530 \% \mathrm{Fe}$, and $0.390 \% \mathrm{Mn}$ with the balance of Al. The ascast material possesses grains of equiaxed shape with an average size of $\sim 140 \mu \mathrm{m}$, and constituent particles are mostly distributed in the interdendritic regions and at grain boundaries, and in particular there is almost no fine dispersoids [4]. Our previous experiments have shown that the concentration level of $\mathrm{Mn}$ in solid solution is about $0.35 \mathrm{wt} . \%$, and the average size for the constituent particles is $0.88 \mu \mathrm{m}$ [4].

The as-received materials were cold rolled at room temperature by multiple passes to an accumulated deformation strain of $\varepsilon=3.0$, these samples were subsequently annealed through three different temperature-time paths, as illustrated in Fig. 1. One set of the deformed sheets were directly annealed in a pre-heated salt bath at: i) $500{ }^{\circ} \mathrm{C}$ for $5 \mathrm{~s}$; and ii) $350{ }^{\circ} \mathrm{C}$ for $10^{5} \mathrm{~s}$, both referred to as as-cast samples (see Fig. 1a). Additional samples were subjected to step annealing where the samples were pre-treated to give material conditions with a certain amount of fine dispersoids. These specimens were isothermally preannealed at $300{ }^{\circ} \mathrm{C}$ for $10^{4} \mathrm{~s}$. They were subsequently annealed at the same conditions as the as-cast samples, as illustrated in Fig. 1b. For the purpose of comparison, one sample was also heated at $50{ }^{\circ} \mathrm{C} / \mathrm{h}$ in a furnace to $350{ }^{\circ} \mathrm{C}$ and held for $10^{5} \mathrm{~s}$ at that temperature (see Fig. 1c). The latter sample is throughout the paper termed as "non-isothermally annealed" sample. After the heat treatments, all samples were quickly water quenched.

For the microstructure characterization details of the annealed samples, the reader is referred to [4], but key information is reiterated here for the convenience of the reader. Metallographic examinations of constituent particles and dispersoids were observed using the backscattered electron (BSE) detector in a Zeiss Supra 55 field emission gun scanning electron microscope (FEG-SEM). Specimens were prepared for electron microscopy by mechanical polishing to $1 \mu \mathrm{m}$, and then electro-polished in a solution of 30 vol.\% nitric acid and methanol at $-30{ }^{\circ} \mathrm{C}$ and $15 \mathrm{~V}$. The crystallographic textures of the sheets were measured by means of Electron backscatter diffraction (EBSD) and TSL software. Orientation maps of the annealed samples, covering more than one thousand grains, with step size of $0.5-2 \mu \mathrm{m}$, were used to study the orientation of the recrystallized grains and thus the recrystallization texture. For all of the micrographs presented below in this paper, the horizontal direction corresponds to the rolling direction (RD) while the vertical direction is the normal direction (ND). The grain size was measured as the equivalent circular diameter in the $\mathrm{RD}-\mathrm{ND}$ cross section. The texture was represented in terms of orientation distribution functions (ODFs) using TSL OIM Analysis 6 software by imposing the Orthotropic (Rolled sheet) symmetry, and using the harmonic series expansion method $(\mathrm{L}=22)$ and a Gaussian halfwidth of $5^{\circ}$ [15].

\section{Results}

\subsection{Different dispersoid structures associated with the time-temperature paths}

The temperature and annealing time for the step annealing were chosen according to our previous studies [4] such that no recrystallization is initiated yet for the first step (further confirmed by Fig. 2a) while a significant amount of fine dispersoids (the electrical conductivity increased $3.3 \mathrm{~m} / \Omega \mathrm{mm}^{2}$ ) have precipitated along grain/subgrain boundaries as can be seen in Fig. 2b. It can be seen that the larger fraction of grain boundaries as well as sub-grain boundaries (cf. Fig. 2) is aligned with the RD direction, thus forming a typical lamellar structure. In Fig. 2c, the sample is heated at $50{ }^{\circ} \mathrm{C} / \mathrm{h}$ to $350{ }^{\circ} \mathrm{C}$ (without holding time), and as observed, the dispersoids in this case are clearly finer and denser than in Fig. 2b. A more comprehensive study on the recrystallization behavior of these conditions can be found in Refs $[13,16]$.

\subsection{Annealing at high temperature}

In addition to the dispersoids obtained after the pre-annealing, the supersaturated Mn (0.35 wt.\%) in solid solution of the investigated Al$\mathrm{Mn}-\mathrm{Fe}-\mathrm{Si}$ alloy will precipitate concurrently with recrystallization as fine dispersoids during back-annealing. To possibly simplify the interpretations, the as-cast and pre-treated samples were annealed at $500{ }^{\circ} \mathrm{C}$ for $5 \mathrm{~s}$, where concurrent precipitation was negligible during this short time. The corresponding microstructures are shown in Fig. 3, where it is also observed that recrystallization was completed

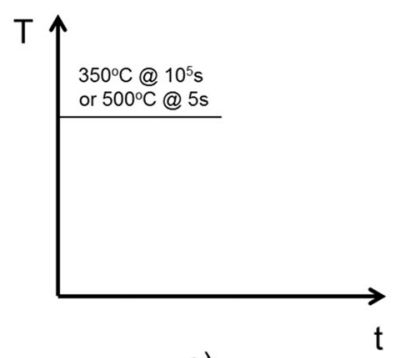

a)

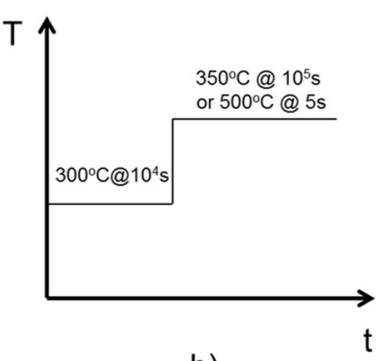

b)

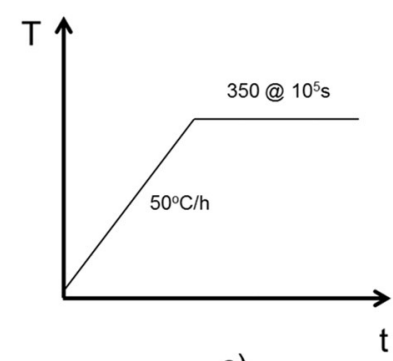

c)

Fig. 1. Schematic graph showing the three temperature-time paths used in the current study. a) Isothermal annealing; b) two-step annealing; c) Non-isothermal annealing. 

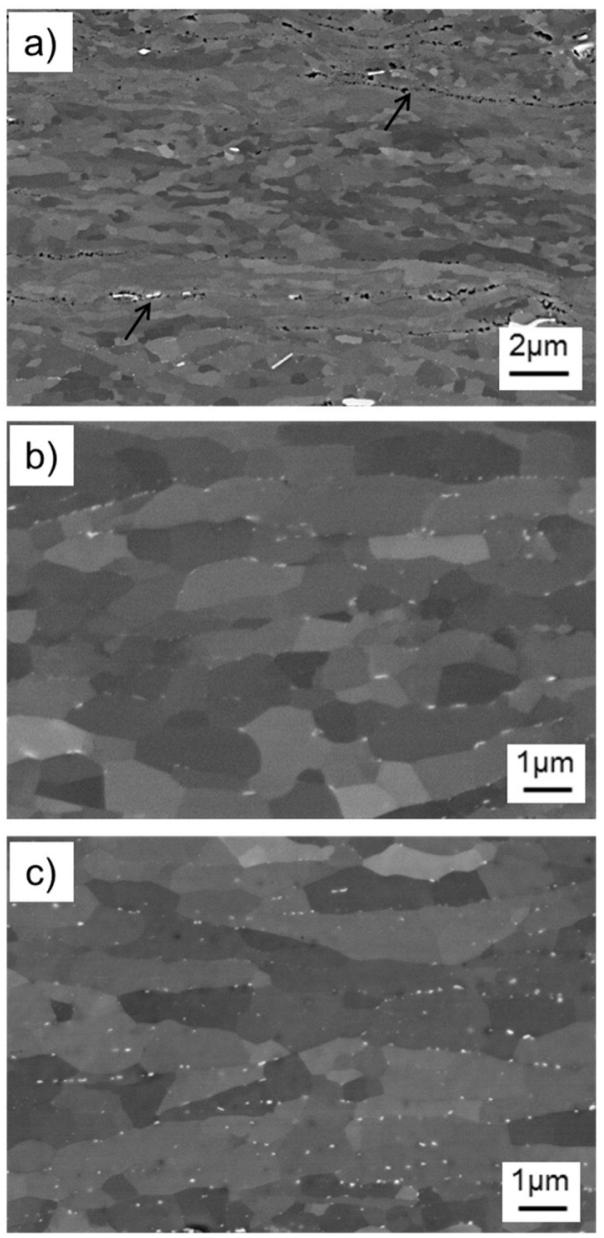

Fig. 2. BSE images showing the microstructure of the deformed samples $(\varepsilon=3.0)$ after annealing at different conditions. a) After isothermal annealing at $300^{\circ} \mathrm{C}$ for $10^{4} \mathrm{~s}$, showing that recrystallization has not yet been initiated. Examples of the high-angle grain boundaries are pointed out by black arrows; b) The same as a), showing the fine dispersoids at grain/sub-grain boundaries; c) After heating at $50{ }^{\circ} \mathrm{C} / \mathrm{h}$ to $350{ }^{\circ} \mathrm{C}$ (with no holding time), showing the smaller concurrently precipitated dispersoids.

for both cases. The recrystallized grain size for the pre-annealed sample (Fig. 3b) is obviously much larger than the as-cast sample (Fig. 3a), which demonstrates that the combined effect of recovery and (concurrent) precipitation during the annealing stage at $300{ }^{\circ} \mathrm{C}$ for $10^{4} \mathrm{~s}$ produces a coarser grain structure. The pre-annealed sample also exhibits slightly more elongated grains.

As shown in Fig. 4, the recrystallization textures for the as-cast and pre-annealed samples are similar, as both of them are dominated by the P and ND-rotated cube texture components. It should also be noted that the intensities of the recrystallization textures are fairly weak for both cases. The most obvious difference is related to the strength and position of the ND-rotated cube component, however in terms of the P texture component, no significant increase was found for the pre-annealed sample which does indeed possess a large number of dispersoids along grain/sub-grain boundaries (see Fig. 2b) before annealing at $500{ }^{\circ} \mathrm{C}$.

\subsection{Annealing at low temperature}

Since it is well documented that the P texture component generally becomes more prominent at lower temperatures [4,6,8], the target annealing temperature was decreased to $350^{\circ} \mathrm{C}$. The recrystallized microstructures for the three cases heated at different temperature-time schedules to $350{ }^{\circ} \mathrm{C}$ and held for $10^{5} \mathrm{~s}$ are shown in Fig. 5. The grain structures are quite similar for these three cases, all with very coarse elongated grains along the RD direction, i.e., very different from the ones in Fig. 3.

Due to the large grain size, a large area $\left(\sim 4 \mathrm{~mm}^{2}\right)$ was scanned by EBSD, to give a statistically reliable representation of the texture for each of the three cases. As shown in Fig. 6, accompanying the much coarser grain structures, stronger textures were indeed presented at the lower annealing temperature of $350{ }^{\circ} \mathrm{C}$ for all three cases as compared to the recrystallization textures at higher temperature (see Fig. 4). The M texture (pointed out by red arrows) component is the dominating one for the as-cast and pre-annealed samples, while for the non-isothermally annealed sample, the P texture component is the strongest $(25 \times$ random $)$. As compared to the non-isothermally annealed sample, the strength of $P$ texture component was $11 \times$ random for the as-cast condition and $7 \times$ random for the one step-annealed.

\section{Discussion}

In this study, the received materials were cold rolled at room temperature by multiple passes to an accumulated deformation strain of $\varepsilon=3.0$. The samples were subsequently annealed through three different temperature-time paths and the recrystallized grain structure and texture analyzed. The results show that although dispersoids along grain/sub-grain boundaries prior to annealing did change the recrystallized grain structure (somewhat coarser) as well as the strength of ND-
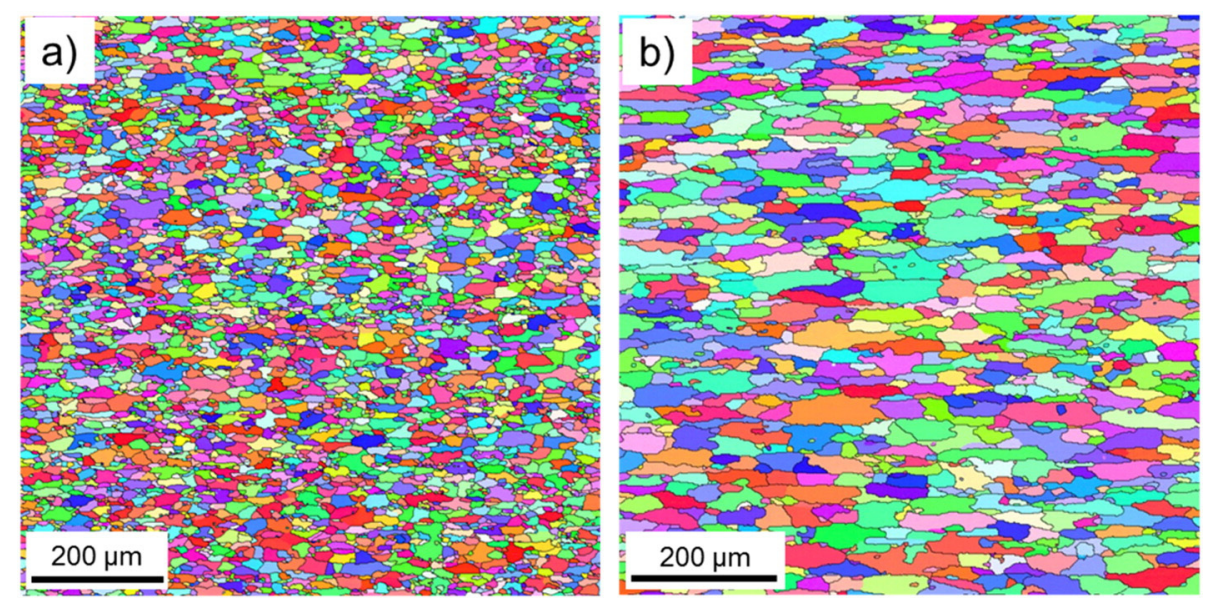

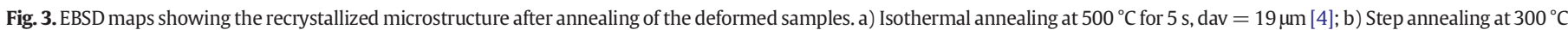
for $10^{4} \mathrm{~s}$ and then at $500{ }^{\circ} \mathrm{C}$ for $5 \mathrm{~s}$, dav $=36 \mu \mathrm{m}$. 

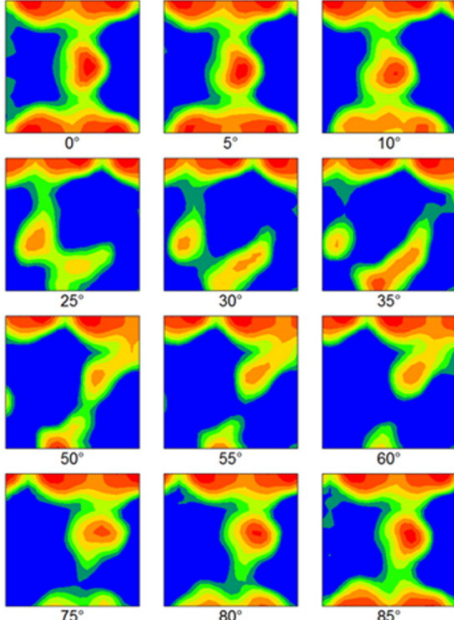

$80^{\circ}$
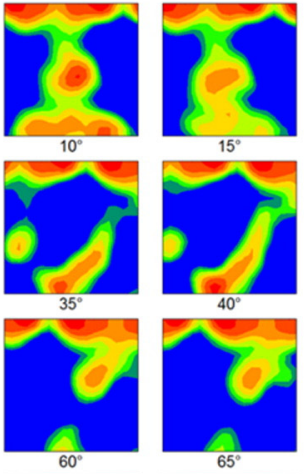

$60^{\circ}$

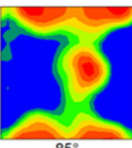

a)
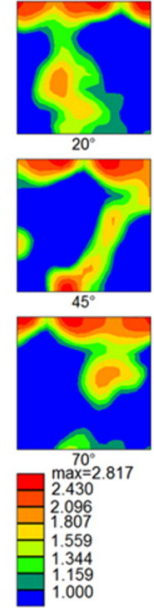
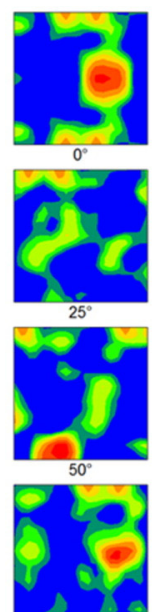

$75^{\circ}$
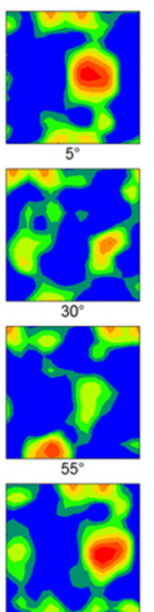

$80^{\circ}$
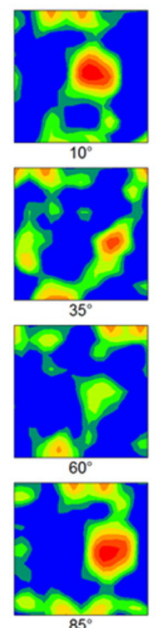

b)
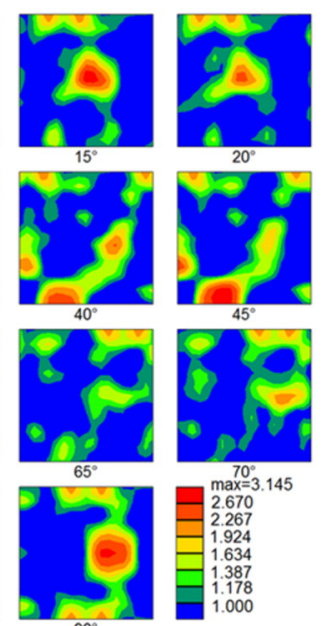

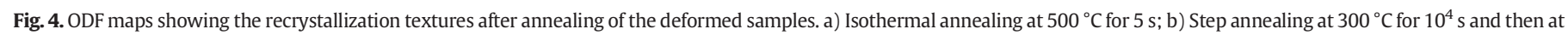
$500{ }^{\circ} \mathrm{C}$ for $5 \mathrm{~s}$

rotated cube component, they did not obviously increase the strength of the P texture, regardless of the annealing temperature. Non-isothermal annealing, on the other hand, promotes a stronger $P$ texture, as well as a more pancake-shaped and much coarser grain structure.

It is generally accepted that the presence of both the P-texture and ND-rotated cube is related to non-deformable constitutive particles and particle stimulated nucleation (PSN) of recrystallization, and it has been demonstrated experimentally by EBSD $[8,13,14,17,18]$ and TEM $[19,20]$ that $P$ and ND-rotated cube oriented grains/sub-grains already are present within the deformation zone around constituent particles after deformation, from which they grow into the surrounding matrix. This fact has further been confirmed by numerical simulations of the texture evolution within the deformation zone of second-phase particles $[21,22]$. It has been speculated that a similar mechanisms applies for the formation of grains with the M orientation [12]. Although both the P-texture and the ND-rotated cube texture components are assumed to have a similar origin, the latter is relatively weak for most of the cases in this study, thus the focus of our discussion is on the P texture component.

The formation of the P texture component depends strongly on annealing temperature and concurrent precipitation. In general, regardless of the temperature-time paths, low temperature annealing of the cold-rolled Al-Mn-Fe-Si alloy lead to coarse elongated grain structure with strong P and/or M textures, see Fig. 6. During annealing at a low temperature of $350^{\circ} \mathrm{C}$, significant amount of precipitation takes place, preferentially at high-angle grain boundaries and subsequently also on low-angle grain boundaries, before the onset of recrystallization and during recrystallization [8]. Both types of boundaries are aligned with the RD direction, as can be seen in Fig. 2. Nucleation at grain boundaries is thus largely suppressed, and only a few orientations (P-, M-oriented grains) can grow out of the deformation zone near the constituent particles, which finally leads to strong M or P texture components. The reason is their special boundary characteristics/orientation relationships with respect to the surrounding deformed matrix (with a typical rolling texture) making them less affected by concurrent precipitation $[7,8]$, and moreover that they have an advantageous orientation relationship for growth [13]. The strength of the M texture component is stronger than that of the P texture component when recrystallization occurs at $350{ }^{\circ} \mathrm{C}$, see Fig. $6 \mathrm{a}$ and $\mathrm{b}$. This is in agreement with earlier work by Liu and Morris [12] in which the evolution of recrystallization texture in a supersaturated $\mathrm{Al}-\mathrm{Mn}$ alloy was investigated at different temperatures. At the very high annealing temperature of $500{ }^{\circ} \mathrm{C}$, recrystallization completes quite fast before significant concurrent precipitation occurs, and none of these three texture components (M, P and ND-rotated cube) are strong (see Fig. 4a). Interestingly, even though a large amount of dispersoids was present along the grain/sub-grain boundaries (see Fig. 2b) before the onset of recrystallization, a very weak texture was still obtained, as illustrated in Fig. 4b. The reason could be that all nucleation mechanisms are mainly still active at high temperatures (controlled by thermally activated processes), and although a certain effect in
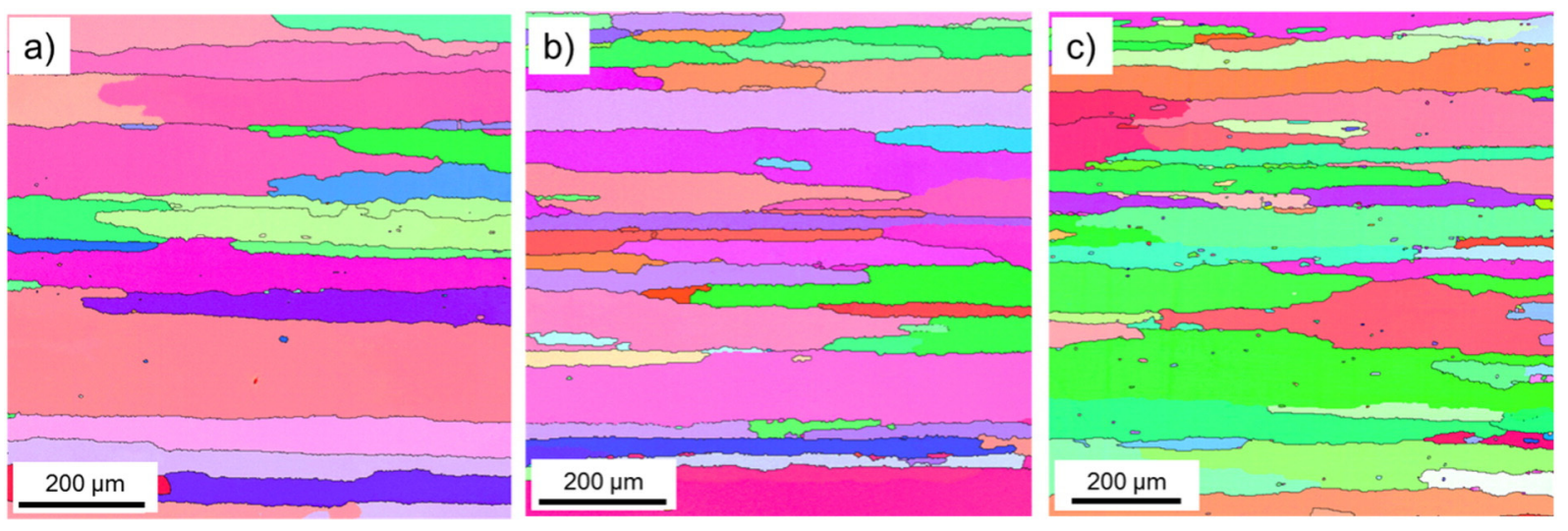

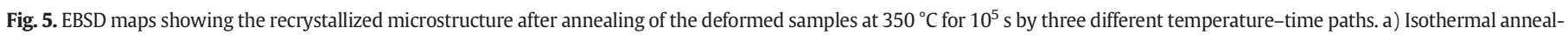
ing; b) Two-step annealing; c) Non-isothermal annealing. 

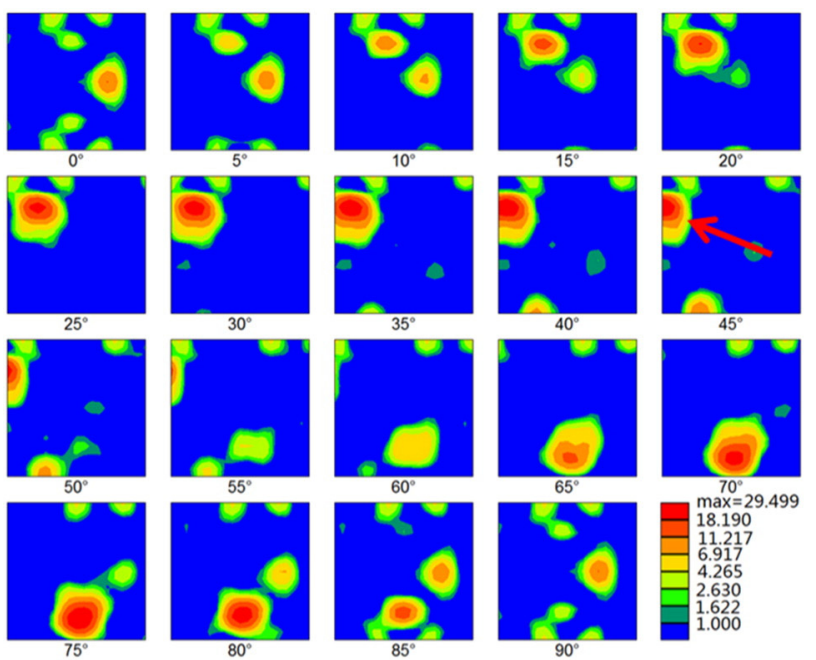

a)
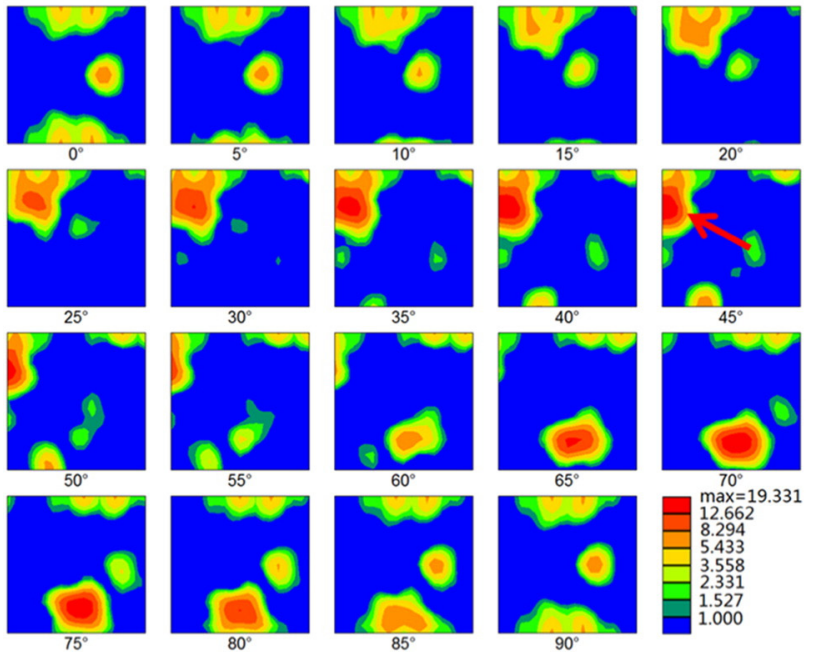

b)
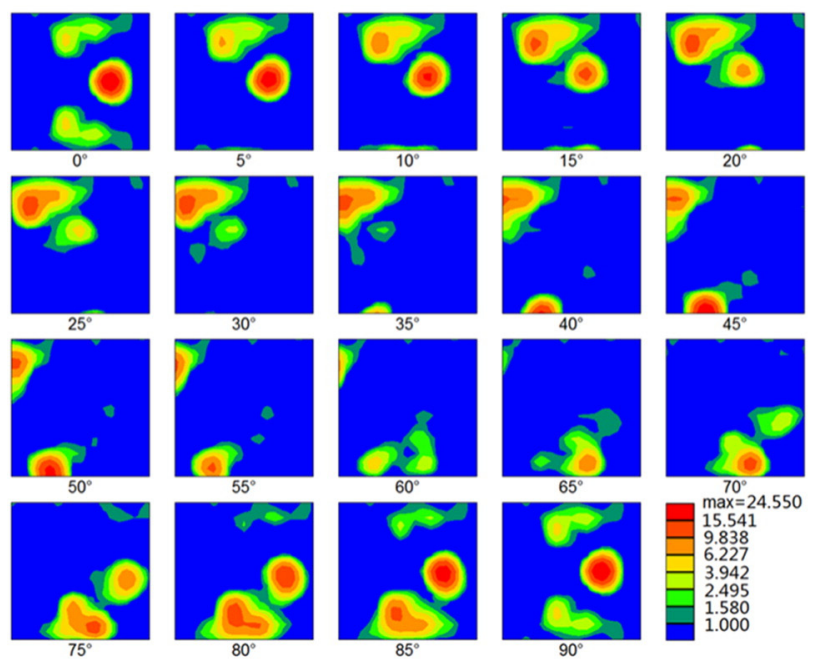
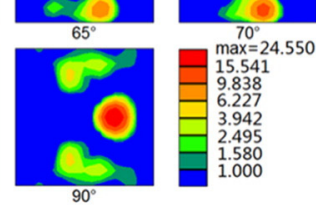

c)

Fig. 6. ODF maps showing the recrystallization textures after annealing of the deformed samples at $350{ }^{\circ} \mathrm{C}$ for $10^{5} \mathrm{~s}$ by three different temperature-time paths. a) Isothermal annealing; b) Two-step annealing; c) Non-isothermal annealing.

suppressing nucleation of recrystallization does exist, giving a coarser and more elongated grain structure (see Fig. 3), it is not reflected in a corresponding change of texture.

In addition to the target annealing temperature, the temperaturetime paths also affected the grain structure and recrystallization textures. Somewhat unexpected, the weakest $\mathrm{P}$ texture is found after recrystallization of pre-annealed samples at $350{ }^{\circ} \mathrm{C}$, as can be seen in Fig. 6. However, due to the pre-annealing this condition also has the lowest potential for concurrent precipitation, and as such the relatively weaker P-texture observed for this condition emphasize the importance of concurrent precipitation to promote the P-texture component. This is supported by observations for non-isothermal annealing, where recovery and precipitation occur prior to and concurrent with recrystallization, and a much more prominent $\mathrm{P}$ texture component is generally developed as can be seen in Fig. $6 c$. Considerable amount of dispersoids were also found located along grain/sub-grain boundaries after preannealing (see Fig. 2b), but these dispersoids did not contribute to a similarly strong $\mathrm{P}$ texture as the ones concurrently precipitated during non-isothermal annealing. The reason is probably that the latter ones are finer and more densely distributed, as indicated from Fig. 2c, and thus more effectively suppress nucleation of recrystallization.

A more comprehensive work focusing on the softening behavior of the same material but with different microchemistry states $[4,13,23]$ and at different annealing conditions is underway. It will hopefully provide more insight into the effects of the pre-existing dispersoids that are located along grain/sub-grain boundaries.

\section{Conclusions}

In this study, a supersaturated as-cast Al-Mn-Fe-Si alloy was annealed at three different temperature-time paths after cold rolling. Dispersoids that are located along grain/sub-grain boundaries were produced prior to annealing and their effect on the subsequent recrystallization behavior of the deformed material in terms of final grain structure and recrystallization texture was investigated. The following conclusions can be drawn from the present work:

- At high annealing temperatures the textures are generally weak, still with a distinct P-component which to a limited extent is affected by pre-existing dispersoids.

- At lower annealing temperatures the effect of grain-/sub-grain boundary dispersoids, whether pre-existing or from concurrent precipitation, have a strong effect on final grain structure giving very coarse and elongated grains. However, pre-existing dispersoids clearly have a less influence on the strength of the P texture component as compared to those formed during recrystallization (concurrent precipitation), most probably because of their larger sizes as compared to the latter ones.

- The strongest P-texture is obtained for conditions of non-isothermal annealing and low annealing temperatures, both factors promoting significant concurrent precipitation, which mainly suppress nucleation and growth of all other orientations, whether from PSN or from other nucleation mechanisms.

\section{Acknowledgments}

This research work has been supported by the KMB project (193179/ I40) in Norway. The financial support by the Research Council of Norway and the industrial partners, Hydro Aluminium and Sapa Technology is gratefully acknowledged. KH acknowledges the financial support from the Norwegian University of Science and Technology through Strategic Area Materials.

\section{References}

[1] Y.J. Li, W.Z. Zhang, K. Marthinsen, Precipitation crystallography of plate-shaped Al$6(\mathrm{Mn}, \mathrm{Fe})$ dispersoids in AA5182 alloy, Acta Mater. 60 (2012) 5963-5974.

[2] Y.J. Li, L. Arnberg, Quantitative study in the precipitation behavior of dispersoids in DC-cast AA3003 alloy during heating and homogenization, Acta Mater. 51 (2003) 3415-3428. 
[3] Y.J. Li, L. Arnberg, Evolution of eutectic intermetallic particles in DC-cast AA3003 alloy during heating and homogenization, Mater. Sci. Eng. A 347 (2003) 130-135.

[4] K. Huang, N. Wang, Y.J. Li, K. Marthinsen, The influence of microchemistry on the softening behaviour of two cold-rolled Al-Mn-Fe-Si alloys, Mater. Sci. Eng. A 601 (2014) 86-96.

[5] M. Somerday, F.J. Humphreys, Recrystallization behavior of supersaturated Al-Mn alloys, Mater. Sci. Technol. 19 (2003) 20-29.

[6] W.C. Liu, J.G. Morris, Evolution of recrystallization and recrystallization texture in continuous-cast AA 3015 aluminum, Metall. Mater. Trans. A 36 (2005) 2829-2848.

[7] H.E. Vatne, O. Engler, E. Nes, Influence of particles on recrystallisation textures and microstructures of aluminium alloy 3103, Mater. Sci. Technol 13 (1997) 93-102.

[8] S. Tangen, K. Sjølstad, T. Furu, E. Nes, Effect of concurrent precipitation on recrystallization and evolution of the P-texture component in a commercial Al-Mn alloy, Metall. Mater. Trans. A 41A (2010) 2970-2983.

[9] K. Marthinsen, N. Wang, K. Huang, Modelling microstructure and properties during annealing of cold rolled Al-Mn-Fe-Si-alloys with different microchemistries, Mater Sci. Forum 783-786 (2014) 57-62.

[10] Q. Zeng, X. Wen, T. Zhai, Effect of precipitates on the development of p orientation $\{011\}<566>$ in a recrystallized continuous cast AA 3004 aluminum alloy after cold rolling, Metall. Mater. Trans. A 40A (2009) 2936-2948.

[11] W.C. Liu, Z. Li, C.-S. Man, Effect of heating rate on the microstructure and texture of continuous cast AA 3105 aluminum alloy, Mater. Sci. Eng. A 47 (2008) 173-180.

[12] W.C. Liu, J.G. Morris, Recrystallization textures of the $M\{113\}<110>$ and $\mathrm{P}\{011\}<455>$ orientations in a supersaturated Al-Mn alloy, Scr. Mater. 56 (2007) 217-220.

[13] K. Huang, O. Engler, Y.J. Li, K. Marthinsen, Evolution in microstructure and properties during non-isothermal annealing of a cold-rolled Al-Mn-Fe-Si alloy with different microchemistry states, Mater. Sci. Eng. A 628 (2015) 216-229.
[14] C. Schäfer, G. Gottstein, The origin and development of the $P\{011\}<111>$ orientation during recrystallization of particle-containing alloys, Int. J. Mater. Res. 102 (2011) 1106-1114.

[15] O. Engler, V. Randle, Introduction to Texture Analysis: Macrotexture, Microtexture and Orientation Mapping, 2nd ed. CRC Press, Boca Raton, FL, 2010.

[16] K. Huang, Q.L. Zhao, Y.J. Li, K. Marthinsen, Two-stage annealing of a cold-rolled Al$\mathrm{Mn}-\mathrm{Fe}-\mathrm{Si}$ alloy with different microchemistry states, J. Mater. Process. Technol. (2015), http://dx.doi.org/10.1016/j.jmatprotec.2015.02.016.

[17] O. Engler, Nucleation and growth during recrystallisation of aluminium alloys investigated by local texture analysis, Mater. Sci. Technol. 12 (1996) 859-872.

[18] O.V. Mishin, A. Godfrey, D. Jull Jensen, N. Hansen, Recovery and recrystallization in commercial purity aluminium cold rolled to an ultrahigh strain, Acta Mater. 61 (2013) 5354-5364

[19] O. Engler, P. Yang, X.W. Kong, On the formation of recrystallization textures in binary Al-1.3\% Mn investigated by means of local, Acta Mater. 44 (1996) 3349-3369.

[20] J.-H. Ryu, D.N. Lee, The effect of precipitation on the evolution of recrystallization texture in AA8011 aluminum alloy sheet, Mater. Sci. Eng. A 336 (2002) 225-232.

[21] C. Schäfer, J. Song, G. Gottstein, Modeling of texture evolution in the deformation zone of second-phase particles, Acta Mater. 57 (2009) 1026-1034.

[22] J.J. Sidor, R.H. Petrov, L.A.I. Kestens, Modeling the crystallographic texture changes in aluminum alloys during recrystallization, Acta Mater. 59 (2011) 5735-5748.

[23] K. Huang YJ. Li, K. Marthinsen, Isothermal annealing of a cold-rolled Al-Mn-Fe-Si alloy with different microchemistry states, Trans. Nonferrous Metals Soc. China 24 (2014) 3840-3847. 